\title{
Theme section of BPMDS'2014: the human perspective in business processes
}

\author{
Selmin Nurcan ${ }^{1}$ - Rainer Schmidt ${ }^{2}$
}

Received: 8 November 2016 / Accepted: 20 November 2016 / Published online: 7 December 2016

(C) Springer-Verlag Berlin Heidelberg 2016

The BPMDS series has produced 11 workshops from 1998 to 2010. Nine of these workshops were held in conjunction with CAiSE conferences. From 2011, BPMDS has become a two-day working conference attached to CAiSE (Conference on Advanced Information Systems Engineering). The topics addressed by the BPMDS series are focused on IT support for business processes. This is one of the keystones of Information Systems theory. The goals, format, and history of BPMDS can be found on the Web site http://www.bpmds. org/

\section{Scope}

This theme section follows the 15th edition of the BPMDS (Business Process Modeling, Development, and Support) series, organized in conjunction with CAISE'14, which was held in Thessaloniki, Greece, June 2014. BPMDS'2014 received 48 submissions from 23 countries, and 20 papers were selected and published in Springer LNBIP 175 volume.

Social production and social interaction became more and more crucial for Business Process Engineering and Management [1]. Social production is the creation of artefacts, combining the input from independent and non-predetermined contributors without predetermining the mechanism by which this is accomplished [2,3]. Although the success of social digital environments is rather new, its roots can be traced to the 1960s and even 1940s [4]. Concepts

Selmin Nurcan

selmin.nurcan@univ-paris1.fr

1 University Paris 1 Panthéon-Sorbonne, Paris, France

2 Munich University of Applied Sciences, Munich, Germany such as Granovetter's weak ties [5,6] foresaw the power of social interactions without knowing the possibility of implementing them using software systems. The basic advantages of using social digital environments in the engineering/execution/management of business processes have been identified in [7]. Key challenges for enabling agile Business Process Management (BPM) with social software have been discussed in [8].

The human perspective is of essence since humans drive business processes rather than computers. This perspective plays a major role in all phases of BPMDS. The human perspective in business process modeling relates to the individual who creates a process model, to the communication among people that is facilitated by the business process model during and after the modeling process, and to the social process of collaborative modeling. The human perspective in business process design relates to the kind of interaction/collaboration/coordination/cooperation that should be implemented in the business process or to specific human-related aspects of the business process itself and their representations in models. Human perspective in business process support relates to all social aspects of the business process and its management in an organization.

This theme section is targeted at both researchers and practitioners in the information systems community with a focus on "The Human Perspective in Business Processes." The six papers in this theme section reflect this focus. Five of them are extensively revised and extended versions of research papers that were initially presented at the BPMDS'2014 working conference and passed again a blind review for the theme section. Another paper has been selected from five additional submissions (not presented in BPMDS'2014) in response to the open call for papers for this theme section. 


\section{Six selected papers for this theme section}

The first paper by C. Crick and E. Chew, "Business processes in the agile organization: a socio-technical perspective," takes a cross-disciplinary view of the ontology of business process: how the concept is treated in the information systems research literature and how related concepts (with stronger human behavioral orientation) from organization and management sciences can potentially inform this information systems perspective. The paper presents a theoretical framework for understanding the role of business processes in organizational agility that distinguishes between the processas-designed and the process-as-practiced. How this practice aspect of business processes also leads to the improvisation of various information technology enablers is explored using a socio-technical lens. The posited theoretical framework is illustrated and validated with data drawn from an interpretive empirical case study of a large IT services company. The research suggests that processes within the organization evolve both by top-down design and by the bottom-up routinization of practice and that the tension between these is driven by the need for flexibility.

The second paper by H. A. Reijers, I. Vanderfeesten, M. Plomp, P. Van Gorp, D. Fahland, W. Van der Crommert, and H.D. Diaz Garcia, "Evaluating data-centric process approaches: Does the human factor factor in?" has been selected from the five papers of the open call. Authors argue that addressing design, improvement, management, support, and execution of business processes, the business process management (BPM) focuses more on developing modeling notations and process design approaches than on the needs and preferences of the individuals who are modeling (business actors). They provide a review of existing data-centric process approaches that have been developed to extend or counter the overly activity-oriented way of designing and executing business processes, as activity-oriented process models had become known for a number of limitations. Data-centric approaches have certain advantages, varying from increasing flexibility in process execution and improving reusability to actually being able to capture processes where data play a relevant role. Authors empirically evaluate three specific approaches with regard to the claims they make. The study let them conclude that usability aspects of process design approaches are crucial and, in the perception of groups representative for actual users, leave much to be desired. They conclude that this research can be seen as a wake-up call for process modeling notation designers to consider the usability side - and as such, the interest of the human modeler-more than is currently the case.

The third paper by I. Bider, E. Perjons, M. Elias, and P. Johannesson,"A Fractal Enterprise Model and its Application for Business Development," suggests a new type of enterprise models called Fractal Enterprise Models (FEM), with accompanying methodological support for their design. FEM shows interconnections between the business processes in an enterprise by connecting them to the assets they use and manage. A FEM model is built by using two types of patterns called archetypes: a process-assets archetype that connects a process with assets used in it, and an assetprocesses archetype that connects an asset with processes aimed to manage this asset. Alternating these patterns creates a fractal structure that makes relationships between various parts of the enterprise explicit. FEM can be used for different purposes, including finding a majority of the processes in an enterprise and planning business change or radical transformation. Besides discussing FEM and areas of its usage, the paper presents results from a completed project in order to test the practical usefulness of FEM and its related methodological support.

The fourth paper by A. Front, D. Rieu, M. Santorum, and F. Movahedian, "A participative end-user method for multiperspective business process elicitation and improvement," proposes ISEA, a participative end-user modeling approach that allows the stakeholders in a business process to collaborate together in a simple way to communicate and improve the business process elicitation in an accurate and understandable manner. The approach covers the organizational perspective of business processes, exploits the information compiled during the elicitation of the organizational perspective, and touches lightly an interactional perspective allowing users to create customized interface sketches to test the user interface navigability and the coherence within the processes. Authors present ISEA as a participative end-user modeling approach for business process elicitation and improvement in order to achieve consensual intermediary products that can be mapped in standard languages. Each intermediary product deals with a specific perspective of the business process.

The fifth paper by D. Knuplesch and M. Reichert, "A visual language for modeling multiple perspectives of business process compliance rules," observes that ensuring the compliance of their business processes with imposed compliance rules stemming from various sources, e.g., corporate guidelines, best practices, standards, and laws is a fundamental challenge for enterprises. Authors remind that a compliance rule may refer to multiple process perspectives including control flow, time, data, resources, and interactions with business partners. They also recall that compliance rules (1) should be comprehensible for domain experts who must define, verify, and apply them, (2) should have a precise semantics to avoid ambiguities and enable their automated processing. The paper argues that providing a visual language is advantageous as it allows hiding formal details and offering an intuitive way of modeling the compliance rules. However, existing visual languages for compliance rule modeling have focused on the control flow perspective, but lack proper support for the other process perspectives. To remedy this 
drawback, this paper introduces the extended Compliance Rule Graph language, which enables the visual modeling of compliance rules with the support of multiple perspectives.

The sixth paper by M. Salnitri, F. Dalpiaz, and P. Giorgini, "Designing secure business processes with SecBPMN," discusses modern information systems which are increasingly large and consist of an interplay of technical components and social actors (humans and organizations). The authors argue that the complexity of these systems and their blending with society calls for new design techniques, for their crashes entail severe effects in the broader societal context where the systems operate. They also advocate that due to the large amount of private and confidential information that they manage, their design shall treat information assurance and security as primary concern from both a social/organizational and a technical perspective. The paper presents the limitations of existing approaches and introduces the SecBPMN framework. The proposal includes (1) the SecBPMN-ml modeling language, a security-oriented extension of BPMN for specifying composite information systems; (2) the SecBPMN-Q query language for representing security policies; and (3) a query engine that enables checking SecBPMN-Q policies against SecBPMN-ml specifications.

Acknowledgements We wish to thank the referees from the BPMDS' 2014 Program Committee members for their timely and accurate reviews during the two-round and blind review process for this theme section, namely Eric Andonoff, Renata Araujo, Judith Barrios, Karsten Boehm, Corine Cauvet, Sergio Espana, Dirk Fahland, Luciano García-Bañuelos, Johny Ghattas, Aditya Ghose, Claude Godart, Guido Governatori, Marite Kirikova, Marcello La Rosa, Jan Mendling, Oscar Pastor, Geert Poels, Hajo A. Reijers, Iris Reinhartz-Berger, Gil Regev, Stefanie Rinderle-Ma, Colette Rolland, Shazia Sadiq, Pnina Soffer, Matthias Weidlich, and Jelena Zdravkovic. We would like to thank the Editors-in-Chief of the Journal of Software and Systems Modeling for agreeing to publish this theme section. We particularly would like to thank Martin Schindler for his support in helping us put this theme section together. Our gratitude goes to all authors, from BPMDS'2014 and from the open call for papers, who made this theme section possible by submitting their work and revising it according to the reviewers' comments.

\section{References}

1. Schmidt, R., Nurcan, S.: BPM and social software. In: Proceedings of the BPM 2008 Workshops, LNBIP 17, pp. 625-634, Springer (2009)

2. Benkler, Y.: The Wealth of Networks : How Social Production Transforms Markets and Freedom. Yale University Press, London (2006)

3. Tapscott, D., Williams, A.: Wikinomics: How Mass Collaboration Changes Everything. Portfolio Hardcover, London (2006)

4. Bush, V.: As we may think. Interactions 3, 35-46 (1996)

5. Granovetter, M.: The strength of weak ties. Am. J. Sociol. 78, 13601380 (1973)

6. Granovetter, M.: The strength of weak ties: a network theory revisited. Sociol. Theory 1, 201-233 (1983)
7. Erol, S., Granitzer, M., Happ, S., Jantunen, S., Jennings, B., Koschmider, A., Nurcan, S., Rossi, D., Schmidt, R., Johannesson, P.: Combining BPM and social software: contradiction or chance? Special Issue of the Software Process: Improvement and Practice Journal on "BPM 2008 Selected Workshop Papers", vol. 22, Issue 6-7, pp. 449-476

8. Bruno, G., Dengler, F., Jennings, B., Khalaf, R., Nurcan, S., Prilla, M., Sarini, M., Schmidt, R., Silva, R.: Key challenges for enabling Agile BPM with social software. Journal of Software Maintenance and Evolution: Research and Practice, Incorporating Software Process: Improvement and Practice, Special Issue on BPM'09 Selected Workshop Papers, vol. 23, Issue 4, pp. 297-326

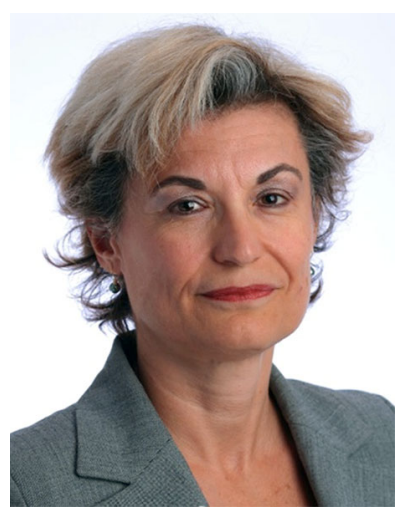

Selmin Nurcan is an Associate Professor at the University Paris 1 Panthéon-Sorbonne and a senior researcher at the 'Centre de Recherche en Informatique' (CRI). She has a $\mathrm{PhD}$ and an engineering degree in Computer Science. Her research interests include enterprise computing, business process management, change modeling, business/IS alignment, IS governance, process (re)engineering, and IS engineering and CSCW. Selmin Nurcan is co-organizer of the BPMDS series at CAISE since 2007, the BPMS2 workshop series at BPM since 2008, and the SoEA4EE workshop series at EDOC since 2009. She is serving on the editorial board of several international journals such us International Journal of Information System Modeling and Design, International Journal of Information Systems in the Service Sector, Requirements Engineering Journal, Journal of Innovation and Learning, and she is the Associate Editor of the e-journal on Advances in Enterprise Systems.

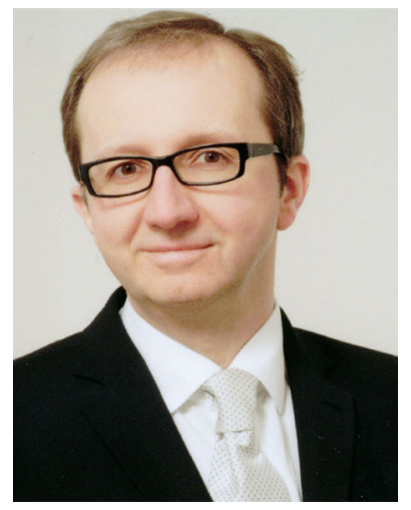

Rainer Schmidt is a Professor for business information systems at Munich University of Applied Sciences. He has a PhD and an engineering degree in Computer Science. His current research areas include service science, enterprise computing, business process management, social software, business/IS alignment and the integration of these themes. $\mathrm{He}$ has industrial experience as management consultant and researcher. Rainer Schmidt is coorganizer of the BPMDS working conference at CAISE, the BPMS2 workshop series at BPM since 2008, the SoEA4EE workshop series in EDOC since 2009, and member of the program committee of several workshops and conferences. Rainer Schmidt is serving on the editorial boards of International Journal of Information Systems in the Service Sector and International Journal on Advances in Internet Technology. Rainer Schmidt applies his research in a number of projects and cooperation with industry. 